\title{
A COMPARATIVE STUDY ON COMMON POWER FLOW TECHNIQUES IN THE POWER DISTRIBUTION SYSTEM OF THE TEHRAN METRO
}

\author{
Mohammad GHIASI
}

\begin{abstract}
Overall, a power-flow study is a steady-state assessment whose goal is to specify the currents, voltages, and real and reactive flows in a power system under a given load conditions. This paper presents a comparison of common power flow techniques in the Tehran metro power distribution system at the presence of non-linear loads. Moreover, a modelling, simulation and analysis of this power distribution system is implemented with the Electrical Transient Analyser Program (ETAP) software. In this assessment, common power flow techniques including the Newton-Raphson (NR), Fast Decoupled (FD), and Accelerated Gauss-Seidel (AGS) techniques are provided and compared. The obtained results (total generation, loading, demand, system losses, and critical report of the power flow) are analysed. In this paper, we focus on the detailed assessment and monitoring by using the most modern ETAP software, which performs numerical calculations of a large integrated power system with fabulous speed and also generates output reports. The capability and effectiveness of the power flow analysis are demonstrated according to the simulation results obtained with ETAP by applying it to the power distribution system of the Tehran metro. In developing countries such as Iran, off-line modelling and simulation of power grids by a powerful software are beneficial and helpful for the best usage of the electrical energy.
\end{abstract}

Keywords: ETAP; modelling; Power Flow Assessment; simulation; Tehran metro

\section{INTRODUCTION 1.1 Background}

The purpose of power flow studies is to plan ahead and account for various hypothetical situations. For instance, if a transmission line is to be taken off line for maintenance, the question is whether the remaining lines in the system can handle the required loads without exceeding their rated values. Power flow is one of the most important tools utilized by electrical experts for the design, planning, control, and analysis needed to determine and specify the best operation for power distribution systems and the exchange of power between utility companies. In the past few years, electrical engineers have been dealing with power system studies by using new software tools. Recent advances in electrical engineering sciences have brought a revolution in the field of electrical engineering after the development of powerful computer-based software [1-4]. A load flow assessment method might take a long time, and hence prevent the achievement of an accurate result for a power flow solution due to continuous changes in power generation and demand. The essential data achieved from a load flow study is the magnitude and phase angle of the voltage at every feeder and bus, and the real and reactive power flowing in every line [5, 6]. Commercial power systems are usually too complex to allow handling solutions for the power flow. Large-scale digital computers have replaced analogous methods with numerical solutions. Moreover, in order for the power flow study to function, computer programs perform related calculations such as short-circuit fault assessment, stability studies with a focus on the transient and steady-state, unit commitment and economic dispatch [7]. Maintaining a high level of system security is one of the more important aspects of power systems that should be noted, as well as the economic operation of these systems $[8,9]$.

\subsection{Literature Review}

In recent years, many researchers have proposed different approaches for the analysis, simulation and modelling in power systems and metro structures. Some recently published papers and literature reviews can be found in [10-14]; the most important factors of metro tunnel safety and the importance of safety and security needed to enable the existence of more comfortable services in metro tunnel and subway stations is explained in [15]; in the reference [16], the criteria and rules for the design of a metro path are discussed; in the paper [17], the authors presented a review of a probabilistic load flow in power systems; the reference [18] deals with the analytical methodology for the assessment of a smart monitoring impact on a future electric power distribution system. In the papers $[19,20]$, new prediction model based on a new feature selection and hybrid prediction engine are introduced.

The Newton-Raphson (NR) power flow, with a consideration of the fuzzy load and in the presence of distributed generations in a distribution network, is presented in [21]. The paper [22] uses a new algorithm for the optimal sizing and sitting of distributed generation in a power system. The summary explanation of the nonlinear of load flow problems is described in the reference [23]. The references $[24,25]$ propose a novel method to deal with energy minimization; and finally in the paper [26], wavelet decomposition combined with an adaptive neuro-fuzzy inference system is used for short-term wind power forecasting. In the reference [27], by using a modified breadth-first search strategy, the improvement of a backward/forward sweep load-flow approach is presented. The goal of the paper [28] is to specify the optimal grid switching condition of minimum losses, with the precondition of keeping the stable voltages on all buses. 


\subsection{Motivation and Main Contribution}

In this paper, the research team focuses on the effective usage of the ETAP software for the load flow assessment and modelling of the electrical power network of the Tehran metro. The results comprise large power distribution systems emanating from high voltage (H.V.), medium voltage (M.V.), and low voltage (L.V.) networks, equipment and loads; the data used for the assessment objective are in the form of one line diagrams of the complete and actual power grid of the Tehran metro starting from HVS and the power transformer at the grid up to the loads. The ratings of all components of the power system network are taken as they actually exist. Moreover, the transformers, load switch (L.S.) and circuit breakers (C.B.), conductor's cables, distribution system and DC components are also simulated according to the actual ratings by the ETAP, and this innovative concept deals with $63 \mathrm{kV}, 20 \mathrm{kV}, 0.75 \mathrm{kV}$ and $0.4 \mathrm{kV}$ network simulations with the ETAP software.

\subsection{Paper Structure}

The remainder of this paper is organized as follows: Section 2 introduces the fundamental theories of the proposed method. Section 3 describes a case study analysis approach to the power distribution system of the Tehran metro in detail. In Section 4, the prediction results are given. The conclusions are presented in Section 5.

\section{MATERIALS AND METHOD}

In this section, three common power flow methods are explained.

\subsection{Bus Classifications}

According to the references [29-32], the feeder bus is a point or node where one or several generators, transmission lines, and loads are connected. It can be said that generally, in every power system analysis, each feeder bus is associated with four quantities: active power $(P)$, reactive power $(Q)$, voltage magnitude $(|V|)$, and voltage phase angle $(\delta)$. Furthermore, feeders are divided into three categories: 1) slack bus, 2) generator (PV) bus, and 3) load (PQ) bus. Those three categories are shown in Tab. 1.

Table 1 Bus classification
\begin{tabular}{|c|c|c|c|c|}
\hline \multirow{2}{*}{ Type of Bus } & \multicolumn{4}{|c|}{ Variables } \\
\cline { 2 - 5 } & $P$ & $Q$ & $V$ & $\delta$ \\
\hline Slack & Unknown & Unknown & Known & Known \\
\hline$(\mathrm{PV})$ & Known & Unknown & Known & Unknown \\
\hline$(\mathrm{PQ})$ & Known & Known & Unknown & Unknown \\
\hline
\end{tabular}

\subsection{Power Flow Calculation Methods}

In the last few decades, for solving load flow analysis problems, several numerical assessment methods have been proposed. It can be said that the most commonly used iterative methods are the Gauss-Seidel (GS), the Fast-
Decoupled (FD), and the FD methods [5, 33]. According to the reference [5], when performing load flow assessment, the first step is to form the Y-bus admittance using the transmission line and the transformer input data. The nodal formula for a study of the power system network using the Y-bus can be given as follows:

$I=Y_{\text {Bus }} V$

The nodal formula can be expressed in a generalized form for a $\mathrm{n}$ bus system as follows:

$I_{i}=\sum_{j=1}^{n} Y_{i j} V_{j} ;$ for $i=1,2,3, \ldots, n$

And the complex power and the current delivered to bus $i$ are given by the following formula:

$P_{i}+j Q_{i}=V_{i} I_{i}^{*}$

$I_{i}=\frac{P_{i}-j Q_{i}}{V_{i}^{*}}$

Replacing for $I_{i}$ in terms of $P_{i}$ and $Q_{i}$, the following formula is given as:

$\frac{P_{i}-j Q_{i}}{V_{i}^{*}}=V_{i} \sum_{j=1}^{n} Y_{i j}-\sum_{j=1}^{n} Y_{i j} V_{j} ; j \neq i$

On the other hand, according to the reference [34], a complex power injection of the system is given by the following formula:

$S_{i}=S_{G i}-S_{D i}=$ Generation - Load

$S_{i}=\sum_{k}^{n} S_{i k}$

where in the Eqs. (6) and (7): $k=1,2, \ldots, n ; i=1,2, \ldots, n$. Similarly, the phasor of current injections is given by the following formula:

$I_{i}=I_{G i}-I_{D i}=\sum_{k}^{n} Y_{i k} V_{i k}$

$\mathrm{S}_{\mathrm{i}}=\mathrm{V}_{\mathrm{i}} \mathrm{I}_{\mathrm{i}}^{*}=\mathrm{V}_{\mathrm{i}} \sum_{\mathrm{k}}^{\mathrm{n}} \mathrm{Y}_{\mathrm{ik}}^{*} \mathrm{~V}_{\mathrm{k}}^{*}$

$S_{i}=\sum_{k}^{n}\left|V_{i}\right|\left|V_{k}\right| \mathrm{e}^{j \delta i k}\left(G_{i k}-j B_{i k}\right)$

where: $V_{k}=\left|V_{k}\right| \mathrm{e}^{i \delta i k} ; \delta_{i k}=\delta_{i}-\delta_{k} ; Y_{i k}=G_{i k}+j B_{i k}$

Breaking down the complexity of power flow formulation into real and imaginary parts is given by the following formula:

$S_{i}=P_{i}+j Q_{i}=\sum_{k}^{n}\left|V_{i}\right|\left|V_{k}\right| e^{j \delta i k}\left(G_{i k}-j B_{i k}\right)$

$P_{i}=\sum_{k}^{n}\left|V_{i}\right|\left|V_{k}\right|\left[G_{i k} \cos \left(\delta_{i k}\right)+B_{i k} \sin \left(\delta_{i k}\right)\right]$

$Q_{i}=\sum_{k}^{n}\left|V_{i}\right|\left|V_{k}\right|\left[G_{i k} \cos \left(\delta_{i k}\right)-B_{i k} \sin \left(\delta_{i k}\right)\right]$

These Eqs. (11), (12), and (13) utilize iterative techniques to solve power flow problems. Therefore, they are necessary to review the general forms of these various solution methods: NR, FD and Accelerated Gauss-Seidel (AGS) power flow. 


\subsubsection{Newton-Raphson Method}

The NR method iteratively solves and formulates the following power flow equation:

$$
\left|\begin{array}{l}
\Delta P \\
\Delta Q
\end{array}\right|=\left|\begin{array}{cc}
1 & J 2 \\
J 3 & J 4
\end{array}\right|\left|\begin{array}{l}
\Delta \delta \\
\Delta V
\end{array}\right|
$$

where in the Eq. (14), $J 1, J 2, J 3$ and $J 4$ are the Jacobean matrix elements. $\mathrm{P}$ and $\mathrm{Q}$ are the specified feeder real and reactive power mismatch vectors between the calculated value and the specified value, respectively; $\Delta V$ and $\Delta \delta$ represent the voltage magnitude of the feeder bus and angle vectors in an incremental form; besides, the elements from $J 1$ to $J 4$ are named Jacobean matrices $[30,32,35,36]$.

\subsubsection{Fast-Decoupled Method}

The FD method originated from the NR method. It takes in the fact that a small variation in the voltage magnitude of the feeder bus does not extremely change the real power at the feeder bus, and also, for a small variation in the phase angle of the feeder bus voltage, the reactive power does not vary too much. Therefore, the equation of the power flow from the NR method can be simplified into two separate decoupled sets of power formulas, which according to the references $[30,32,35,36]$ can be solved iteratively:

$$
\begin{aligned}
& |\Delta P|=|J 1||\Delta \delta| \\
& |\Delta Q|=|J 1||\Delta V|
\end{aligned}
$$

It can be said that compared to the N-R method, the FD method reduces the storage of computer memory by almost half. It also solves the power flow formulas by taking substantially less computer time than that required by the NR method, due to the fact that Jacobean matrices are constant $[30,32,35,36]$.

\subsubsection{Accelerated Gauss-Seidel Method}

Based on the equation of the system nodal voltage:

$|I|=\left|Y_{\text {Bus }}\right||V|$

The AGS method derives the following power flow formula and solves it iteratively:

$|P+j Q|=\left|V^{T}\right|\left|Y_{B u s}^{*} V^{*}\right|$

where in the Eq. (17), $P$ and $Q$ are the specified bus real and reactive power vectors, $V$ is the voltage vector of the feeder bus; $Y_{B u s}$ is the admittance matrix of the system. $Y_{B u s}^{*}$ and $V^{*}$ are the conjugates of $Y_{B u s}$ and $V$, respectively. $V^{\mathrm{T}}$ is the transpose of $V[30,32,35,36]$.

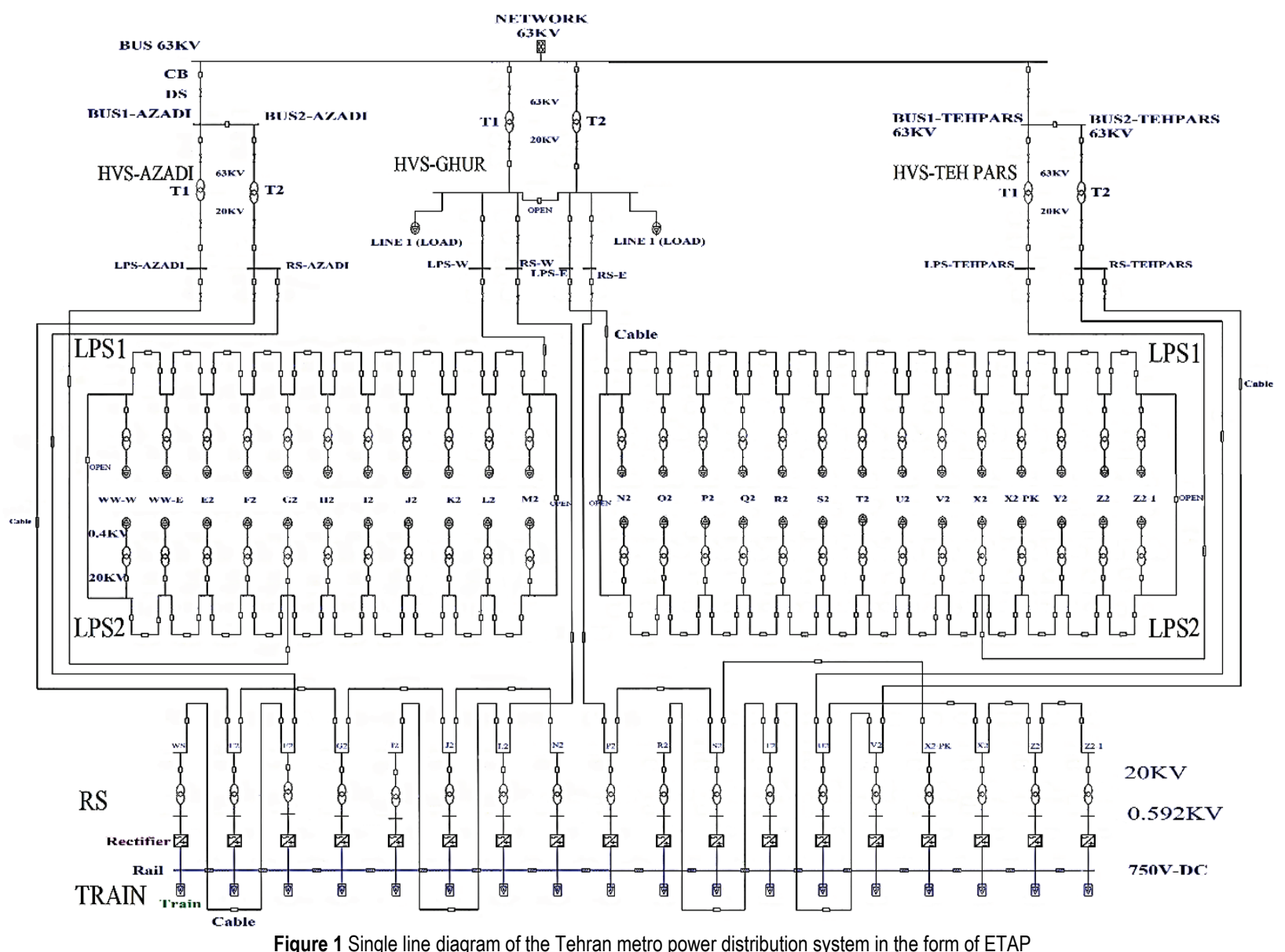


Table 2 LPS information data

\begin{tabular}{|c|c|c|c|c|}
\hline Station & LPS & $\mathrm{kW} \cdot \mathrm{h}$ & $\mathrm{kVAr} \cdot \mathrm{h}$ & $\%$ P.F \\
\hline \multirow{2}{*}{ WWW } & LPS1 & 13210 & 12610 & 0.7233555 \\
\hline & LPS2 & 88820 & 58220 & 0.8363717 \\
\hline \multirow{2}{*}{ WWE } & LPS1 & 104430 & 46830 & 0.9125093 \\
\hline & LPS2 & 79240 & 59440 & 0.8011232 \\
\hline \multirow{2}{*}{ E2 } & LPS1 & 134450 & 87650 & 0.8377593 \\
\hline & LPS2 & 164460 & 105100 & 0.8427737 \\
\hline \multirow{2}{*}{ F2 } & LPS1 & 75070 & 62450 & 0.7687251 \\
\hline & LPS2 & 79880 & 46860 & 0.8626003 \\
\hline \multirow{2}{*}{ G2 } & LPS1 & 82290 & 52870 & 0.8413779 \\
\hline & LPS2 & 48610 & 43880 & 0.7428379 \\
\hline \multirow{2}{*}{$\mathrm{H} 2$} & LPS1 & 98420 & 59290 & 0.8568776 \\
\hline & LPS2 & 65630 & 42300 & 0.8398448 \\
\hline \multirow{2}{*}{ I2 } & LPS1 & 70240 & 63610 & 0.7410854 \\
\hline & LPS2 & 66650 & 54620 & 0.7733361 \\
\hline \multirow{2}{*}{$\mathrm{J} 2$} & LPS1 & 77460 & 71430 & 0.7350218 \\
\hline & LPS2 & 50470 & 49840 & 0.7113282 \\
\hline \multirow{2}{*}{ K2 } & LPS1 & 81080 & 100250 & 0.6263911 \\
\hline & LPS2 & 39090 & 54660 & 0.5812381 \\
\hline \multirow{2}{*}{ L2 } & LPS1 & 63610 & 90670 & 0.5745531 \\
\hline & LPS2 & 85820 & 96680 & 0.6640755 \\
\hline \multirow{2}{*}{ M2 } & LPS1 & 104430 & 88290 & 0.7638856 \\
\hline & LPS2 & 104000 & 87100 & 0.7700215 \\
\hline \multirow{2}{*}{$\mathrm{N} 2$} & LPS1 & 28700 & 36100 & 0.6204821 \\
\hline & LPS2 & 123500 & 90100 & 0.8083965 \\
\hline \multirow{2}{*}{$\mathrm{O} 2$} & LPS1 & 55220 & 57500 & 0.6919053 \\
\hline & LPS2 & 121230 & 94300 & 0.7895626 \\
\hline \multirow{2}{*}{ P2 } & LPS1 & 135640 & 80500 & 0.8601678 \\
\hline & LPS2 & 51650 & 23300 & 0.9107287 \\
\hline \multirow{2}{*}{ Q2 } & LPS1 & 36460 & 27100 & 0.8010550 \\
\hline & LPS2 & 22470 & 34900 & 0.5412459 \\
\hline \multirow{2}{*}{ R2 } & LPS1 & 145280 & 108700 & 0.8007934 \\
\hline & LPS2 & 38490 & 24100 & 0.8479983 \\
\hline \multirow{2}{*}{$\mathrm{S} 2$} & LPS1 & 159100 & 114610 & 0.8112439 \\
\hline & LPS2 & 41300 & 39100 & 0.7278902 \\
\hline \multirow{2}{*}{$\mathrm{T} 2$} & LPS1 & 156100 & 112100 & 0.8118303 \\
\hline & LPS2 & 28210 & 20500 & 0.8102244 \\
\hline \multirow{2}{*}{$\mathrm{U} 2$} & LPS1 & 154100 & 115900 & 0.7996264 \\
\hline & LPS2 & 36000 & 32500 & 0.7432941 \\
\hline \multirow{2}{*}{ V } & LPS1 & 165500 & 119410 & 0.8111439 \\
\hline & LPS2 & 6620 & 8410 & 0.6178215 \\
\hline \multirow{2}{*}{$\mathrm{X}$} & LPS1 & 53300 & 26100 & 0.8984435 \\
\hline & LPS2 & 143610 & 40500 & 0.9626290 \\
\hline & LPS1 & 143252 & 93292 & 0.8380018 \\
\hline Y 2 & LPS2 & 44735 & 7475 & 0.9863348 \\
\hline 7 ר & LPS1 & 58049 & 20251 & 0.9446808 \\
\hline$Z 2$ & LPS2 & 120174 & 54718 & 0.9101126 \\
\hline 72 & LPS1 & 24266 & 43813 & 0.4842675 \\
\hline $2 L-1$ & LPS2 & 21245 & 24950 & 0.6485155 \\
\hline $\mathrm{Y} 2$ & LPS1 & 78410 & 36810 & 0.9052369 \\
\hline$X \angle-P K$ & LPS2 & 44420 & 26010 & 0.8629317 \\
\hline
\end{tabular}

\section{CASE STUDY}

According to the reference [37], the line 2 of the Tehran metro is supplied from three high voltage substations (HVS) and consists of 154 main feeders. All HVSs in the power network of the Tehran metro comprise $63 / 20 \mathrm{kV}$ and a gas insulated substation (GIS) type. Each station of the Tehran metro has two lighting and power substations (LPS). The LPSs supply electric power for the equipment and loads. The LPS is located at each substation platform. The rectifier substation (RS) converts AC to DC power to supply electrical energy for the traction motors of trains. Most stations on line 2 of the Tehran metro have one RS. Each RS is capable to convert $20 \mathrm{kV}$ (AC) to $750 \mathrm{~V}$ (DC) using diode rectifiers. A single line diagram of the Tehran metro power distribution system in the form of ETAP is displayed in Fig. 1.

As shown in Fig. 1, HVSs are located at the top, LPSs and loads at the middle, and RSs and loads at the bottom. According to the monthly report (August 2017) from the Tehran metro power distribution unit, the total consumption for LPSs and RSs (active and reactive) are measured, and that informational data are presented in Tab. 2 and Tab. 3, respectively.

Table 3 RS information data

\begin{tabular}{|c|c|c|c|}
\hline Station $-\mathrm{RS}$ & $\mathrm{kW} \cdot \mathrm{h}$ & $\mathrm{kVAr} \cdot \mathrm{h}$ & $\% \mathrm{P} . \mathrm{F}$ \\
\hline $\mathrm{WW}$ & 38020 & 7020 & 0.9834531 \\
\hline $\mathrm{E} 2$ & 258020 & 35020 & 0.9909234 \\
\hline $\mathrm{F} 2$ & 305030 & 51030 & 0.9863063 \\
\hline $\mathrm{G} 2$ & 365040 & 69030 & 0.9825968 \\
\hline $\mathrm{I} 2$ & 389050 & 69040 & 0.9846302 \\
\hline $\mathrm{J} 2$ & 313060 & 55050 & 0.9849100 \\
\hline $\mathrm{L} 2$ & 408070 & 72060 & 0.9847835 \\
\hline $\mathrm{N} 2$ & 291080 & 46070 & 0.9877354 \\
\hline $\mathrm{P} 2$ & 365090 & 62020 & 0.9858781 \\
\hline $\mathrm{R} 2$ & 292100 & 51010 & 0.9850876 \\
\hline $\mathrm{S} 2$ & 292500 & 47010 & 0.9873774 \\
\hline $\mathrm{T} 2$ & 222100 & 32030 & 0.9897701 \\
\hline $\mathrm{U} 2$ & 198020 & 27000 & 0.9901485 \\
\hline $\mathrm{V} 2$ & 195030 & 23050 & 0.9931157 \\
\hline $\mathrm{X} 2$ & 236040 & 30010 & 0.9920170 \\
\hline $\mathrm{Y} 2$ & 198050 & 51020 & 0.968391 \\
\hline $\mathrm{Z} 2$ & 206000 & 51030 & 0.9709646 \\
\hline $\mathrm{Z} 2-1$ & 217010 & 55000 & 0.9704049 \\
\hline
\end{tabular}

For the implementation of this simulation, the values used to compare the three methods of load flow are shown in Tab. 4.

Table 4 The values of power flow methods

\begin{tabular}{|c|c|c|c|}
\hline Method & Max Iteration & Precision & Accel. Factor \\
\hline NR & 10 & 0,0001 & - \\
\hline FD & 99 & 0,0001 & - \\
\hline AGS & 2000 & 0,00001 & 1,45 \\
\hline
\end{tabular}

\section{RESULTS AND ANALYSIS OF THE POWER FLOW}

Tab. 5 shows the summary report of branch losses (Max. Loading) in the power distribution grid of the line 2 of the Tehran metro.

Table 5 Branch losses summary report (Max Loading)

\begin{tabular}{|c|c|c|}
\hline \multirow{2}{*}{ Method } & \multicolumn{2}{|c|}{ Losses Branch (Transformers, Cables) } \\
\cline { 2 - 3 } & $\mathrm{kW}(P)$ & $\mathrm{kVAr}(Q)$ \\
\hline NR & 1494.61 & 18168.20 \\
\hline FD & 1494.62 & 18168.22 \\
\hline AGS & 1494.61 & 18168.21 \\
\hline
\end{tabular}

As it can be seen from Tab. 5, the results of all three methods are very close together.

As it can be seen, the results of these three load flow methods are almost exactly the same; hence, due to the similarity of the results in each of the three load flow simulations, the critical reports of the NR load flow are illustrated in Fig. 2 and 3 respectively. Fig. 2 shows the amount of under voltage $(\mathrm{kV})$ in different distribution 
transformers. Fig. 3 shows the percentage of overload on transformers. The marginal and critical voltage drop and overload standard set by utility are $2 \%$ and $5 \%$ respectively, and here they are significantly violated. The summary of the total generation, loading and demand for the maximum loading of the case study are shown in Tab. 6.

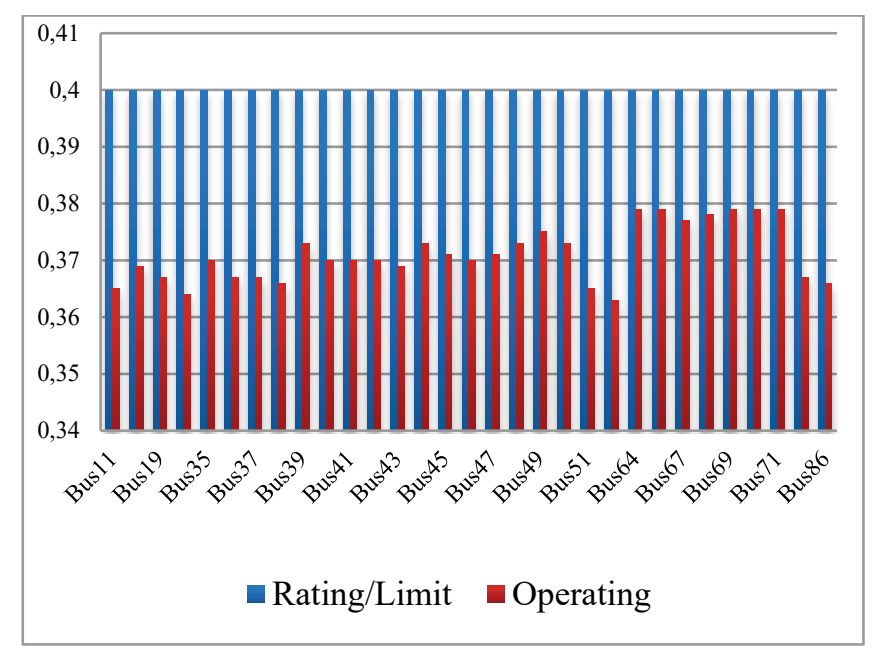

Figure 2 Voltage drop (kV) on the buses

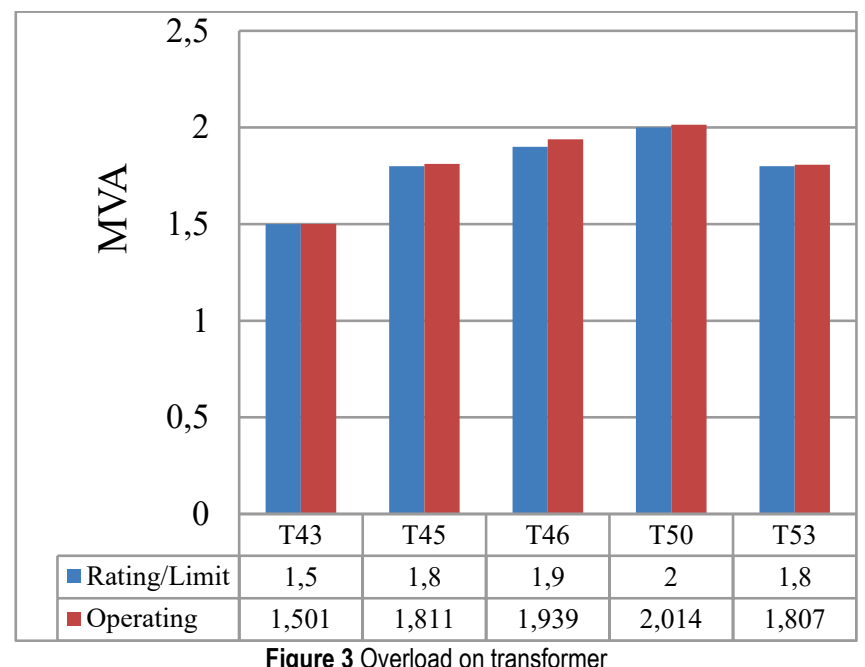

Table 6 Summary of total generation, loading and demand (Max. Loading)

\begin{tabular}{|c|c|c|c|c|}
\hline Type & MW (P) & MVAr (Q) & MVA (S) & $\%$ P.F \\
\hline Source & 97.824 & 83.84 & 128.345 & $\begin{array}{c}73.22 \\
\text { Lagging }\end{array}$ \\
\hline Total Demand & 97.824 & 83.084 & 128.345 & $\begin{array}{c}76.22 \\
\text { Lagging }\end{array}$ \\
\hline Total Motor Load & 86.764 & 58.037 & 104.385 & $\begin{array}{c}83.12 \\
\text { Lagging }\end{array}$ \\
\hline Total Static load & 9.566 & 6.878 & 11.782 & $\begin{array}{c}81.19 \\
\text { Leading }\end{array}$ \\
\hline Apparent Losses & 1.495 & 18.168 & - & - \\
\hline
\end{tabular}

\section{CONCLUSION}

In this paper, a case study of the modelling, simulation and power flow analysis of the actual power distribution system of the Tehran metro (Line 2) in the presence of nonlinear loads by using the ETAP was implemented.
Furthermore, a comparison of three common power flow techniques was presented. The theoretical and practical approaches of load flow have been learned, compared, and applied to solve the given tasks. The results of power flow assessment (total generation, loading, demand, and power losses) were obtained and analysed. The numerical methods of the power flow (Newton-Raphson, Fast-Decoupled, and Accelerated- Gauss-Seidel) were compared. Moreover, a power flow based simulation using the ETAP were developed to find the optimum location of the distribution system unit for a load profile improvement and the minimization of power losses in the test distribution system. By using a powerful software such as ETAP for speed performance and computational accuracy is very practical and helpful, and it also offers a better view of the power network for analysis. In a developing country such as Iran, it is highly beneficial that off-line modelling includes the active and reactive power flows, current flow in every branch, PF correction, reliability analysis, etc. of a large electrical power system. Additionally, understanding the best way of the power flow is economical, and therefore it can be a hot topic for future studies of the power distribution system.

\section{Nomenclature}

$\begin{array}{ll}A C & \text { Alternating current } \\ B & \text { Susceptance }\left(\Omega^{-1}\right) \\ D C & \text { Direct current } \\ G & \text { Conductance }\left(\Omega^{-1}\right) \\ I & \text { Current }(\mathrm{A}) \\ I^{*} & \text { Conjugate of } I \\ J & \text { Jacobian matrix } \\ n & \text { Number of branch }(i, k) \\ P & \text { Active power }(\mathrm{kW}) \\ Q & \text { Reactive power }(\mathrm{kVAr}) \\ P V & \text { Generator bus } \\ P Q & \text { Load bus } \\ S & \text { Apparent power }(\mathrm{kVA}) \\ V & \text { Voltage }(\mathrm{V}) \\ V^{*} & \text { Conjugate of } V \\ V^{T} & \text { Transpose of } V \\ V i & \text { Voltage at node } i(\mathrm{~V}) \\ |V| & \text { Voltage Magnitude } \\ Y & \text { Admittance }\left(\Omega^{-1}\right) \\ Y \text { Bus } & \text { Conjugate of } Y_{\text {Bus }} \\ i, j \text { and } k & \text { Indices of buses } \\ \delta & \text { Phase angle of voltage (degree, rad) } \\ \Delta & \text { Mismatch } \\ \mathrm{P} . \mathrm{U} & \text { Per unit } \\ \mathrm{kVA} & \text { Kilo volt ampere } \\ \mathrm{kVAr} & \text { Kilo var }\end{array}$

\section{List of abbreviations}

$\begin{array}{ll}\text { RS } & \text { Rectifier Substation } \\ \text { LPS } & \text { Lighting and Power Substation } \\ \text { HVS } & \text { High Voltage Substation } \\ \text { P.F } & \text { Power Factor } \\ \text { GIS } & \text { Gas Insulated Substation }\end{array}$




\section{REFERENCES}

[1] Brown, K., Shokooh, F., Abcede, H., \& Donner, G. (1990). Interactive simulation of power systems: ETAP applications and techniques. in Industry Applications Society Annual Meeting, Conference Record of the 1990 IEEE, 1930-1941. https://doi.org/10.1109/IAS.1990.152451

[2] Zhongxi, W. \& Xiaoxin, Z. (1998). Power system analysis software package (PSASP)-an integrated power system analysis tool. Proceedings. POWERCON'98, International Conference on Power System Technology, 7-11. https://doi.org/10.1109/ICPST.1998.728602

[3] Stagg, G. W. \& El-Abiad, A. H. (1968). Computer methods in power system analysis. McGraw-Hill.

[4] Khan, R. A. J., Junaid, M., \& Asgher, M. M. (2009). Analyses and monitoring of $132 \mathrm{kV}$ grid using ETAP software. ELECO 2009, International Conference on Electrical and Electronics Engineering, I-113-I-118.

[5] Afolabi, O. A., Ali, W. H., Cofie, P., Fuller, J., Obiomon, P., \& Kolawole, E. S. (2015). Analysis of the Load Flow Problem in Power System Planning Studies. Energy and Power Engineering, 7, 509. https://doi.org/10.4236/epe.2015.710048

[6] Andersson, G. (2004). Modelling and analysis of electric power systems. EEH-Power Systems Laboratory, Swiss Federal Institute of Technology (ETH), Zürich, Switzerland.

[7] Low, S. H. (2013). Convex relaxation of optimal power flow: A tutorial. Bulk Power System Dynamics and Control - IX Optimization, Security and Control of the Emerging Power Grid (IREP), 2013 IREP Symposium, 1-15. https://doi.org/10.1109/IREP.2013.6629391

[8] Akbary, P., Ghiasi, M., Pourkheranjani, M. R. R., Alipour, H., \& Ghadimi, N. (2017). Extracting appropriate nodal marginal prices for all types of committed reserve. Computational Economics, 1-26. https://doi.org/10.1007/s10614-017-9716-2

[9] Tomičić, B., Havaš, L., \& Srpak, D. (2018). Influence of strands transposition on current distribution and power losses in windings of ac machines. Tehnički glasnik, 12(2), 86-92. https://doi.org/10.31803/tg-20180301185613

[10] Zerigui, A., Dessaint, L.-A., Hannat, R., King, R. T. A., \& Kamwa, I. (2015). Statistical approach for transient stability constrained optimal power flow. IET Generation, Transmission \& Distribution, 9, 1856-1864. https://doi.org/10.1049/iet-gtd.2014.0689

[11] Purchala, K., Meeus, L., Van Dommelen, D., \& Belmans, R. (2005). Usefulness of DC power flow for active power flow analysis. Power Engineering Society General Meeting, IEEE, 454-459. https://doi.org/10.1109/PES.2005.1489581

[12] Ding, T., Bie, Z., Bai, L., \& Li, F. (2016). Adjustable robust optimal power flow with the price of robustness for large-scale power systems. IET Generation, Transmission \& Distribution, 10, 164-174. https://doi.org/10.1049/iet-gtd.2015.0561

[13] Ran, X. \& Miao, S. (2016). Three-phase probabilistic load flow for power system with correlated wind, photovoltaic and load. IET Generation, Transmission \& Distribution, 10, 3093-3101. https://doi.org/10.1049/iet-gtd.2016.0424

[14] Kesilmiş, Z., Erol, H., \& Uçman, M. (2018). Power optimization in partially shaded photovoltaic systems. Tehnički glasnik, 12(1), 34-38. https://doi.org/10.31803/tg-20180201165044

[15] Ghiasi, V., Ghiasi, S., Omar, H., Ebrahimi, B., \& Ghiasi, M. (2010). A Review of Metro Tunnel safety Parameters and Role of Risk management, Tehran Metro. Presented at the Fourth International Symposium on Tunnel Safety and Security, Frankfurt am Main, Germany.
[16] Ghiasi, V., Omar, H., Yusoff, Z. B. M., Huat, B. K., Muniandy, R., Ghosni, N. et al. (2010). Design Criteria of Subway Tunnels. Australian Journal of Basic and Applied Sciences, 4, 5894-5907.

[17] Chen, P., Chen, Z., \& Bak-Jensen, B. (2008). Probabilistic load flow: A review. DRPT 2008, Third International Conference on Electric Utility Deregulation and Restructuring and Power Technologies, 1586-1591. https://doi.org/10.1109/DRPT.2008.4523658

[18] Ahadi, A., Ghadimi, N., \& Mirabbasi, D. (2015). An analytical methodology for assessment of smart monitoring impact on future electric power distribution system reliability. Complexity, 21, 99-113. https://doi.org/10.1002/cplx.21546

[19] Ghiasi, M., Irani Jam, M., Teimourian, M., Zarrabi, H., \& Yousefi, N. (2017). A new prediction model of electricity load based on hybrid forecast engine. International Journal of Ambient Energy, 1-8. https://doi.org/10.1080/01430750.2017.1381157

[20] Ghiasi, M., Ahmadinia, E., Lariche, M., Zarrabi, H., \& Simoes, R. (2018). A New Spinning Reserve Requirement Prediction with Hybrid Model. Smart Science, 1-10. https://doi.org/10.1080/23080477.2018.1460890

[21] Darabadi, M., Hashemi, F., Ghadimi, N., \& Ataei, A. (2011). Newton-raphson load flow with consideration of the fuzzy load and in the presence of the distributed generations in distribution network. The $10^{\text {th }}$ International Conference on Environment and Electrical Engineering (EEEIC 2011), 1-5. https://doi.org/10.1109/EEEIC.2011.5874834

[22] Ghadimi, N. (2014). Using HBMO algorithm to optimal sizing \& sitting of distributed generation in power system. Bulletin of Electrical Engineering and Informatics, 3, 1-8. https://doi.org/10.12928/eei.v3i1.179

[23] Gazijahani, F. S., Ajoulabadi, A., \& Safar, A. (2017). Robust Bilevel Model for Optimal Allocation and Design of Power System Stabilizer in MultiMachine Power Systems. International Journal of Control and Automation, 10, 67-86. https://doi.org/10.14257/ijca.2017.10.9.07

[24] Sun, C., Zhu, S., \& Shi, Z. (2016). Energy Minimization Model Based Target Tracking. National Academy Science Letters, 39, 1-4. https://doi.org/10.1007/s40009-015-0413-1

[25] Heidary Yazdi, S. S., Milimonfared, J., Fathi, S. H., \& Rouzbehi, K. (2018). Optimal placement and control variable setting of power flow controllers in multi-terminal HVDC grids for enhancing static security. International Journal of Electrical Power \& Energy Systems, 102, 272-286. https://doi.org/10.1016/j.ijepes.2018.05.001

[26] Ranganayaki, V. \& Deepa, S. (2017). SVM Based Neuro Fuzzy Model for Short Term Wind Power Forecasting. National Academy Science Letters, 40, 131-134. https://doi.org/10.1007/s40009-016-0521-6

[27] Alinjak, T., Pavić, I., \& Stojkov, M. (2017). Improvement of backward/forward sweep power flow method by using modified breadth-first search strategy. IET Generation, Transmission \& Distribution, 11, 102-109. https://doi.org/10.1049/iet-gtd.2016.0566

[28] Stojkov, M., Softić, A., \& Atić, M. (2015). Optimization of switching conditions in distribution power subsystem. Tehnički vjesnik, 22, 1297-1303.

[29] Elgerd, O. I. (1983). Electric energy systems theory: an introduction. Tata McGraw-Hill.

[30] Kothari, D. P. \& Nagrath, I. (2003). Modern power system analysis. Tata McGraw-Hill Education.

[31] Nitve, B. \& Naik, R. (2014). Steady state analysis of IEEE-6 Bus System Using PSAT power toolbox. International Journal 
of Engineering Science and Innovative Technology (IJESIT) Volume, 3.

[32] Saadat, H. (1999). Power system analysis. WCB/McGraw-Hill.

[33] Keyhani, A., Abur, A., \& Hao, S. (1989). Evaluation of power flow techniques for personal computers. IEEE transactions on power systems, 4, 817-826. https://doi.org/10.1109/59.193857

[34] Karim, K. A., Cheow, N. C., \& Onn, L. K. (2012). Load Flow Analysis of a Test Distribution: A Case Study. Journal of Applied Sciences Research, 8, 5213-5218.

[35] Grainger, J. J. \& Stevenson, W. D. (1994). Power system analysis. McGraw-Hill.

[36] Glover, J. D., Sarma, M. S., \& Overbye, T. (2012). Power System Analysis \& Design. SI Version: Cengage Learning.

[37] Ghiasi, M. \& Olamaei, J. (2016). Optimal capacitor placement to minimizing cost and power loss in Tehran metro power distribution system using ETAP (A case study). Complexity, 21, 483-493. https://doi.org/10.1002/cplx.21828

\section{Authors' contacts:}

Mohammad GHIASI, PhD Student

Metro College, University of Applied Science and Technology, Tehran, Iran

Power Control Center (PCC), Tehran Metro, Tehran Urban and Suburban Railway

Operation Company (TUSRC), Tehran, Iran

Tel: +98-937-4550691

E-mail: Ghiasi1984@gmail.com; M.Ghiasi@IEEE.org 